\title{
A Rasch Analysis on Total Learning Experience of UKM Engineering Students
}

\author{
Azrilah Abdul Aziz ${ }^{1}$, Nuraini Khatimin ${ }^{1}$, Khairul Anwar Mastor ${ }^{2}$, Azami Zaharim ${ }^{1} \&$ Siti Hanani Mat Yasin ${ }^{1}$ \\ ${ }^{1}$ Centre for Engineering Education Research, Fakulti Kejuruteraan dan Alam Bina, Universiti Kebangsaan \\ Malaysia, Selangor, Malaysia \\ ${ }^{2}$ Centre for General Studies, Universiti Kebangsaan Malaysia, Selangor, Malaysia \\ Correspondence: Azrilah Abdul Aziz, Centre for Engineering Education Research, Universiti Kebangsaan \\ Malaysia, 43600 UKM Bangi, Selangor, Malaysia. Tel: 60-389-216-451/6030. E-mail: azrilah@gmail.com
}

Received: February 7, 2013 Accepted: April 7, 2012 Online Published: May 30, 2013

doi:10.5539/ies.v6n6p202 URL: http://dx.doi.org/10.5539/ies.v6n6p202

\begin{abstract}
Learning experience has always been influenced by not only the academic materials presented to students, but also others factors within the surroundings of the students. Assessment is conducted to monitor the students' total learning experience (TLE) throughout their academic tenure-ship at the higher learning institution. UKM has taken the initiative to assess their students' TLE annually. The findings then serve as their benchmark on the enhancement of the facilities provided and the progression of the students' characteristics. UKM prepared a comprehensive TLE assessment on the infrastructure provided, the soft skill development and on personality traits. This paper discusses the findings on UKM's engineering students' TLE in relation to the infrastructure provided by UKM. The students perceived that they learned more from their industrial training provided with mean measured at -1.10 logit. Where else, the least contributing factor towards the students' learning experience is the college facilities with mean measured at +0.50 logit.
\end{abstract}

Keywords: total learning experience, infrastructure influence, TLE assessment, students' perception, Rasch measurement model

\section{Introduction}

Universiti Kebangsaan Malaysia (UKM) has always paid the attention to the learning experience of their students through consistent and well planned efforts on providing a conducive learning environment. The emphasis will, in hope, give maximum impact to the development of student learning progress through the enforcement of the comprehensive policy DPM UKM (2009). UKM wanted its students not only to excel in academic but also having confidence, leadership and promoting national identity internationally.

Learning process involve many things surrounding the person. It does not only mean to disseminate technical knowledge but also include the environment factors, the experiences, and the learning styles of the person (Keefe, 1979; Stewart \& Felicetti, 1992; Chalabine, 2008). Dewey $(1938,1944)$ argued that education and learning are social interactive processes, and thus the school itself is a social institution through which social reform takes place.

Learning experience simply relates students experience towards their internal cognitive development processes. Learning is a process whereby knowledge is created through the transformation of experience (Kolb, 1984). Kolb (1984) emphasized that learning takes place in four cycles and learners have to go through all these cycles for effective learning to take place. The cycles initially involve experiencing new situation or the reinterpreting of existing experience. It then influences the students to review the situation and reflect it back to the experience to understand the phenomena. Subsequently, triggers new ideas or modification to the existing experience which the individual may use the idea later to adopt to new situation or environment (McLeod, 2010). Figure 1 summarised the learning process cycles. 


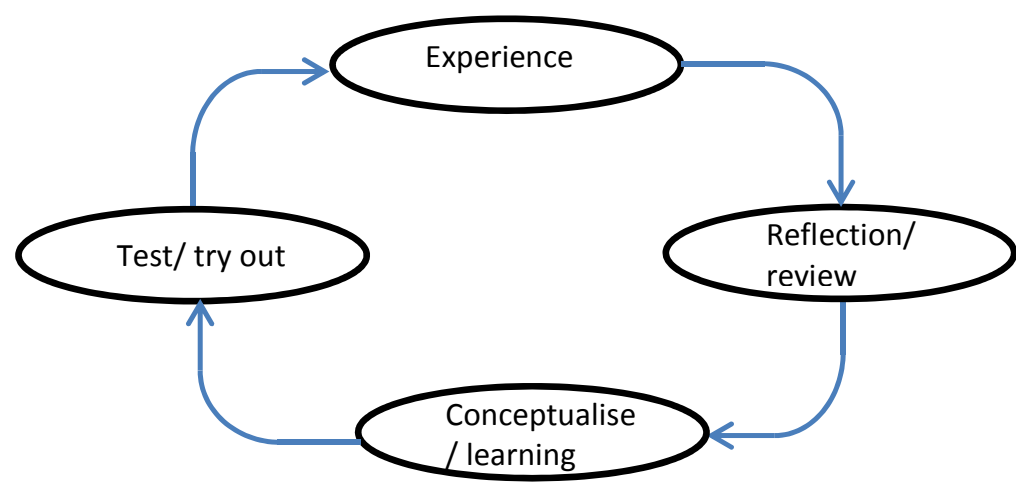

Figure 1. Stages of learning styles

Most famous universities all over the world have already emphasized on the learning environment within their institutions for the students. Kolb (1984) quoted Lewinian model and Dewey's model of learning as similar, where both stressed that learning experience is a process of observing the surrounding, knowledge gained from the surroundings and the judgment of putting together of what is observed and what is recalled to see what they signify. In fact, learning is a continuous process in which the learning experience is very much influence by the surroundings.

The learning experience will be well embedded in the subconscious mind of the students, giving significant whole life impact on the knowledge, skills, attitudes and conscience. Characteristics of such learning experience not only enhanced students' achievement, but will encourage and enhance the internationalization image of the institution. UKM are emphasizing these issues on the students through outbound mobility programs allowing students to apply the experience in life job (Prosser, 2008).

UKM realised that whatever the students learned during their academic tenure-ship gave a big impact to the students' upbringing thus quality for the students. Therefore, UKM made an effort to assess the students' total learning experience every end of each year, in order to monitor the progress of their students' learning experience. Subsequently, the findings will then be used to enhance the surroundings that might have influenced the students.

\section{Method}

The instrument used to assess the students' perception is a survey comprising of 4 segments. First segment contains items to seek the students' perception on the infrastructure provided by UKM. Second segment focuses on the soft skill development and the third segment is on personality traits, while the last segment seeks the students' demographic detail. The segment on infrastructure will be focused for the purpose of this paper. The paper discusses on how the elements under infrastructure have impacted on the students' learning experience in UKM.

\subsection{Instrument (Infrastructure Domain)}

There are eleven (11) elements under infrastructure that will be investigated (Prosser, 2008, DPM UKM, 2009). The elements are factors surrounding the students in the institutions and that might have has influence them during their academic tenure. The elements are their place of residence in the institution, the college, the faculty that they belong to, sports that they take part in, the industrial training that they had to underwent, the co curriculum activities, the social activities that they joint, virtual communication on campus, art and cultural activities, library facilities, internalization, and entrepreneurship. In total there will be only 69 items that will be assessed under infrastructure segment.Students were asked to rate their perception between 1 to 5 ; 1 being "Least disagree" and 5 represent "Highly agree".

\subsection{Sample}

The students participated in this study come from the 12 faculties in all the 3 clusters within UKM; from social sciences, science technologies and engineering, and medical clusters. However for the purpose of this paper, it will only focus on the 100 engineering students from across all cohorts that is from year 1 to year 4 . Rasch measurement model analysis makes it possible for small sample size and small number of items be used in the study with as near as $95 \%$ confidence (Linacre, 1994). The demography description is coded so that it will be easier to reflect them on the Wright map (Lunz, 2012). 


\section{Rasch Mesurement Model}

Rasch measurement model enables measurement to be done on latent trait, similar to day-to-day scientific measurement like measuring weight or distances (Rasch, 1960; Andrich, 1988). A measurement tool should have the property of having equal interval between the measures, which then enable it to predict future phenomena on the sample and have a unit measurement (Wright \& Mok, 2004). The tool should also be able to overcome missing data whereby the data are required to make estimation of what future data look like (Wright, 1992; Wright \& Mok, 2004).

The idea first initiated from a Danish mathematician, Geog Rasch, when he wanted to measure the reading capabilities of student. He is a student of R.A. Fisher best known for his Fisher Exact Test, and Ragnar Frisch whom is famous for his Frisch Probability Theory. Rasch model is a probabilistic model and has the algebraic form of logit-linear models (Linacre, 2004). It treats an event as a likelihood of event occurs over the probability of not happening. For an event to be successful, it took into consideration of both the ability of person in handling the situation and the difficulty of the task itself (Andrich, 1988). In Rasch, the probability of success can be estimated for the maximum likelihood of an event as;

$$
\mathrm{P}(\theta)=\frac{\mathrm{e}\left(\beta_{\mathrm{n}}-\delta_{\mathrm{i}}\right)}{1+\mathrm{e}^{\left(\beta_{\mathrm{n}}-\delta_{\mathrm{i}}\right)}}
$$

where;

$\mathrm{e} \quad=$ base of natural logarithm or Euler's number; 2.7183

$\beta_{\mathrm{n}} \quad=$ person's ability

$\delta_{\mathrm{i}} \quad=$ item or task difficulty

\section{Findings and Discussion}

The responses were tabled and run in Rasch measurement model software, WinSteps. The Cronbach alpha value from the summary statistics is 0.94 indicating a high consistency in the raw score. Figure 2 of the summary statistics showed a very good ability spread of the sample involved in this study with 0.94 person reliability value (Fisher, 2007). The item reliability is at 0.92 indicating a good spread of item difficulties among the items prescribed in this study (ibid). The mean person is given at +0.80 logit indicating that in general these group of engineering students accepted that the infrastructure provided by UKM has made a significant impact on their total learning experience.

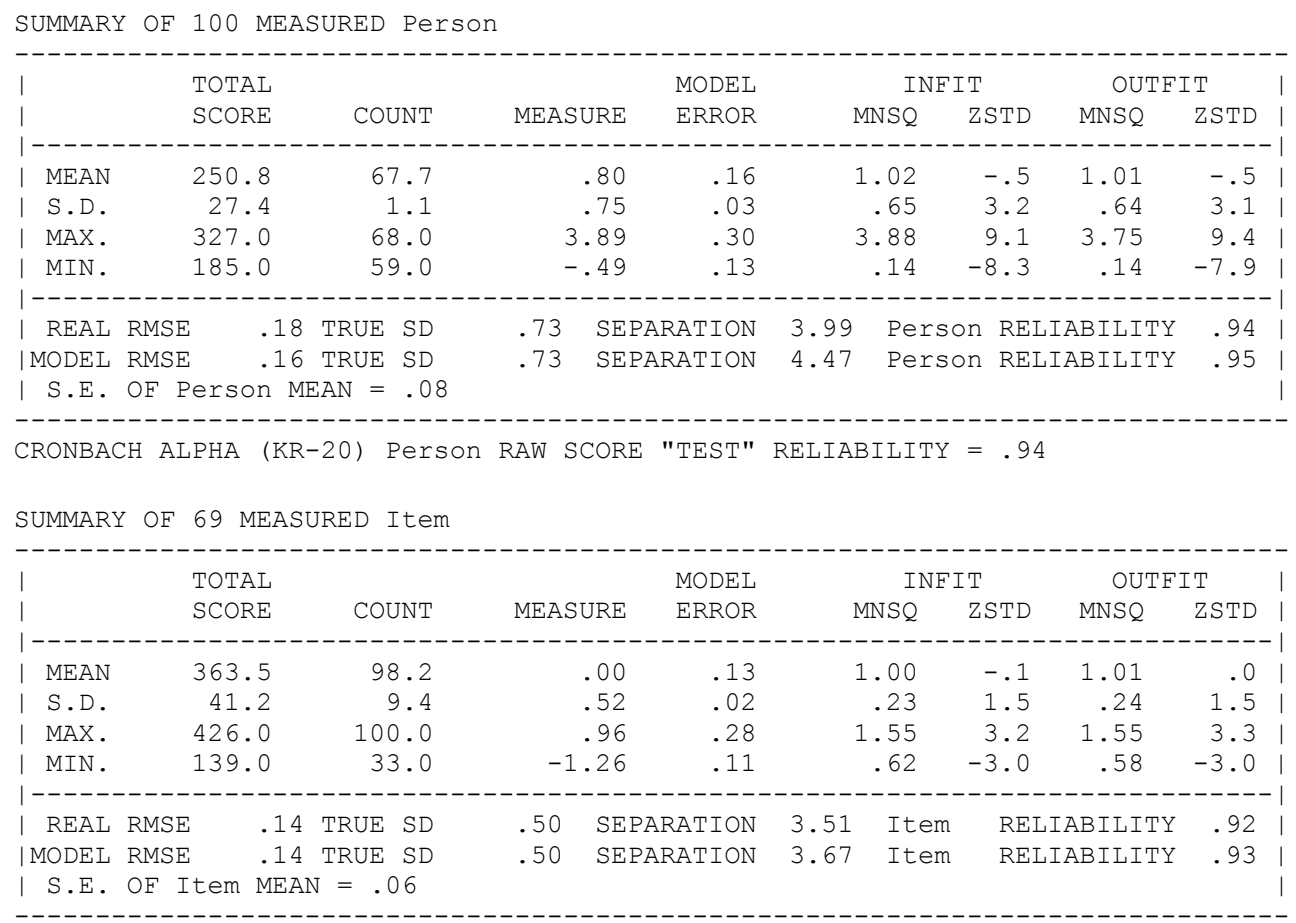

Figure 2. Summary statistics 


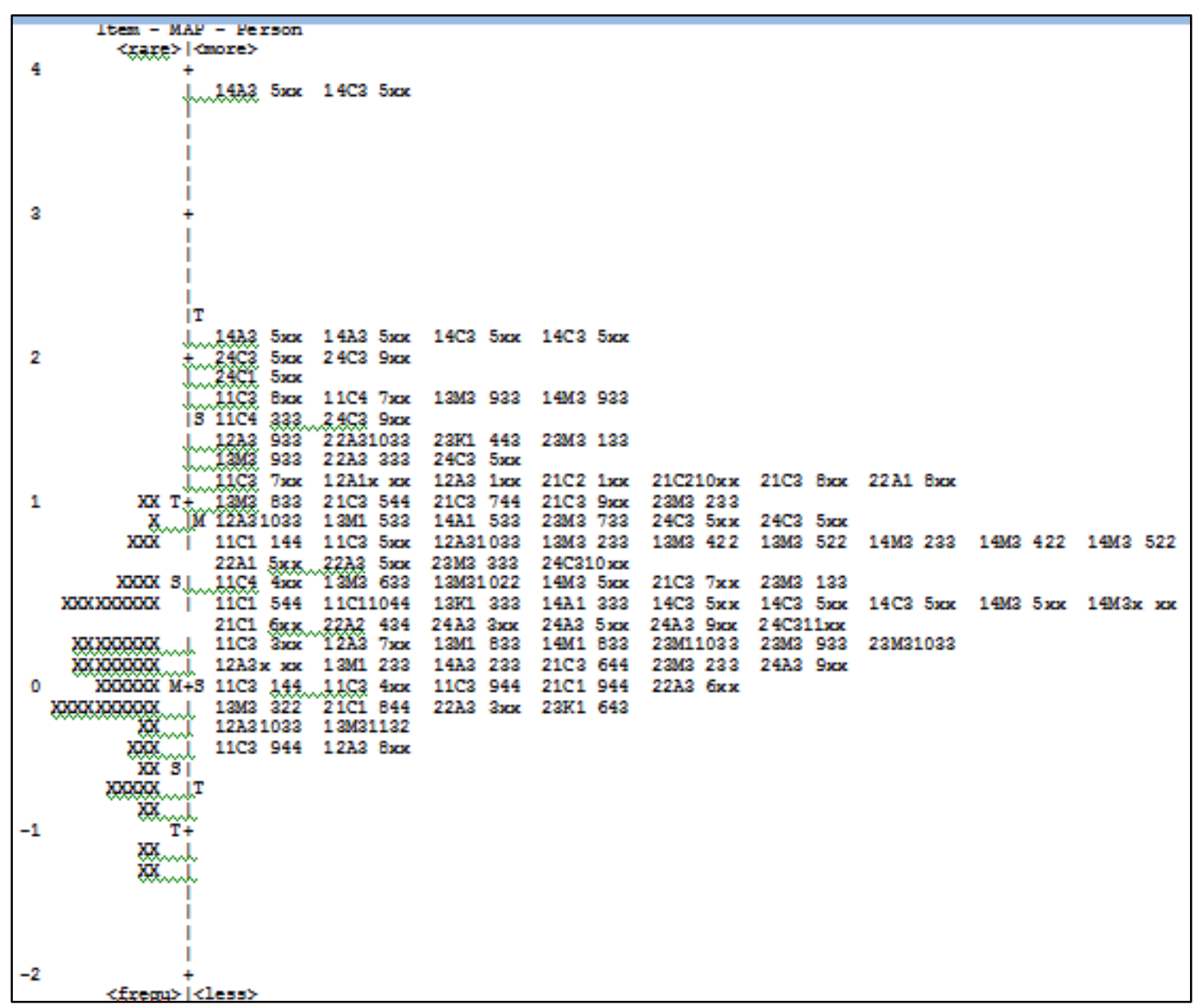

Figure 3. Wright map indicating the spread of person and item according to their respective ability/difficulty measure

Summary statistics also revealed the maximum location of the student being at +3.89 logit on the measurement ruler as in Figure 3 of the Wright map (Lunz, 2012; Wilson, 2011). The maximum location indicates that both the students; $14 \mathrm{C} 35 \mathrm{xx}$ and $14 \mathrm{~A} 35 \mathrm{xx}$, as in Figure 3 of person measure order, agree that infrastructure had made a significant impact on their learning experience. The minimum location of the student, whom disagree the most that the infrastructure played a significant role in influencing his learning experience, is located at -0.49 logit. The least disagree student is coded as 11C3944 whom is a first year male student with grade CGPA of 4.00 from chemical process unit.

Similarly, the summary statistics also revealed the maximum location and the most difficult item that is located at +0.96 logit. The item is a_AlamMaya1 which seeks the students' satisfaction on the computer and broadband facilities provided at the university, which in this case is the most unsatisfied item. On the other hand, the minimum location item and the most satisfied item is located at -1.26 logit, which is item a_LI_3b. Refer to Figure 4. The item seeks the students' opinion on whether they would increase their practical skill or not after the industrial training exercise. It is interesting to note that, a_LI_3b seeks opinion of student who has not undergone the industrial training, while item a_LI_3a seeks students' perception after they undergone the training. The students seem to disagree that they have increase their practical skill after attended the industrial training with gap difference of 0.47 logit. Even though it is a small gap, however this should be investigated further on the reason of such perception.

There are 11 sub-constructs under the infrastructure construct and mapping the mean value of each sub-construct reveals the most and least preferred facilities impacted the students learning experience. The map is as shown in Figure 4. The students indicated that Industrial training made the most impact on their learning experience compared to college facilities provided with mean value of -1.12 logit and +0.5 logit respectively. 
There are only four (4) sub-constructs that students perceived made an impact towards their learning experience; according to most likeness to least; industrial training, library, sports, and co-curricular. While the other seven (7) which students perceived to have least significant impact on the students' learning experience; college, internationalization, arts, entrepreneurship, faculties, cyberworld and community/social.

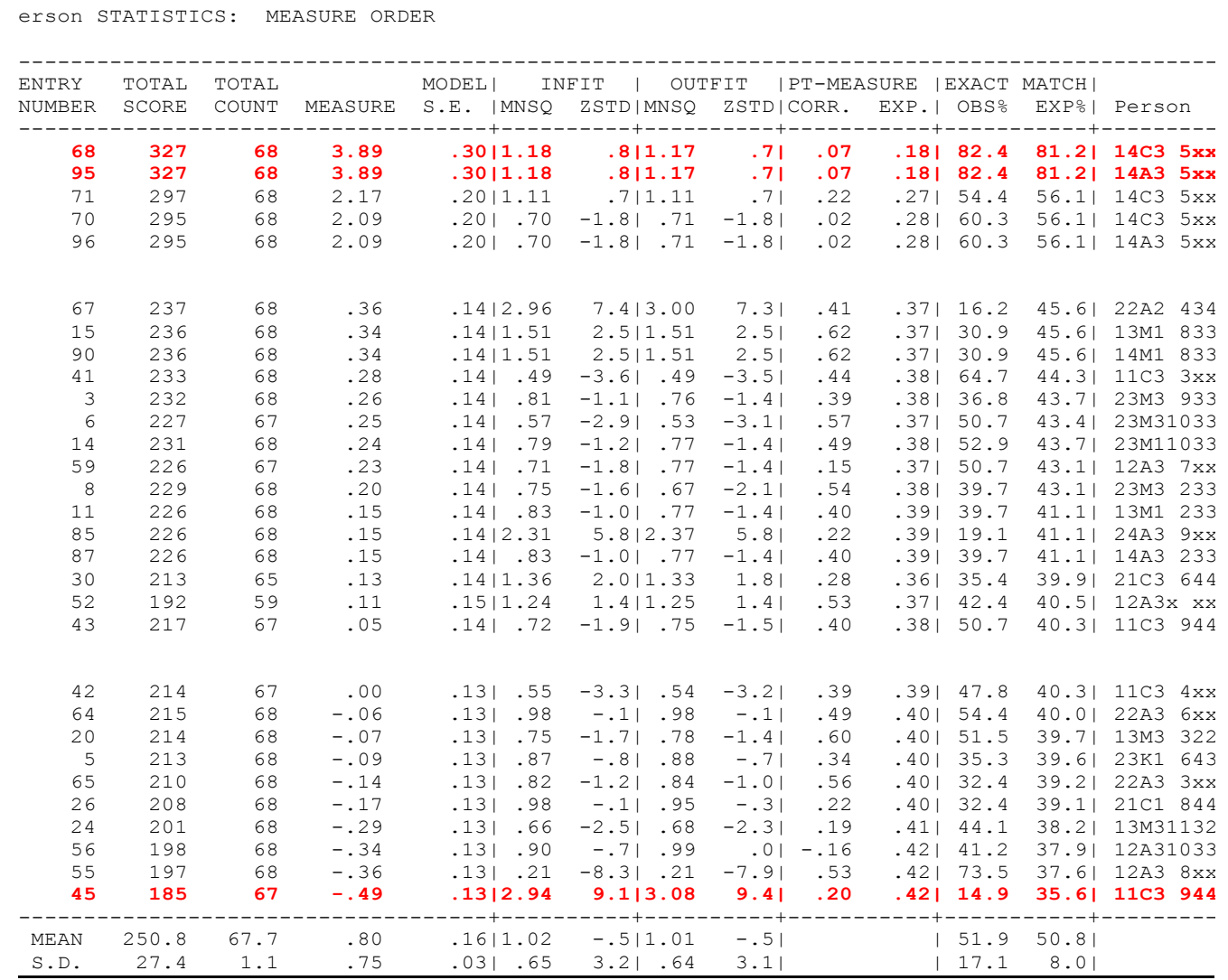

Figure 3. Person measure order

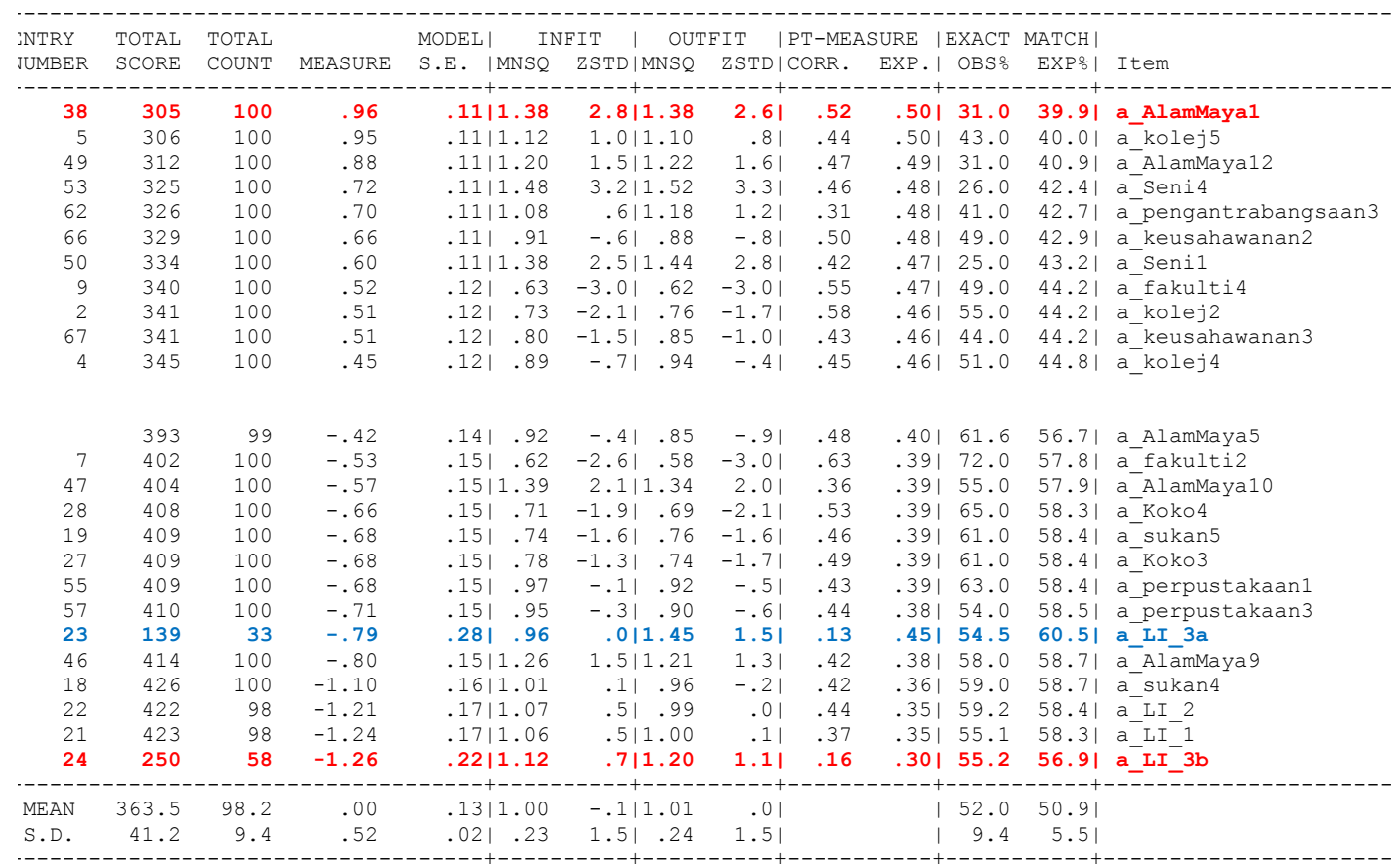

Figure 4. Extraction from Item Measure order Table 


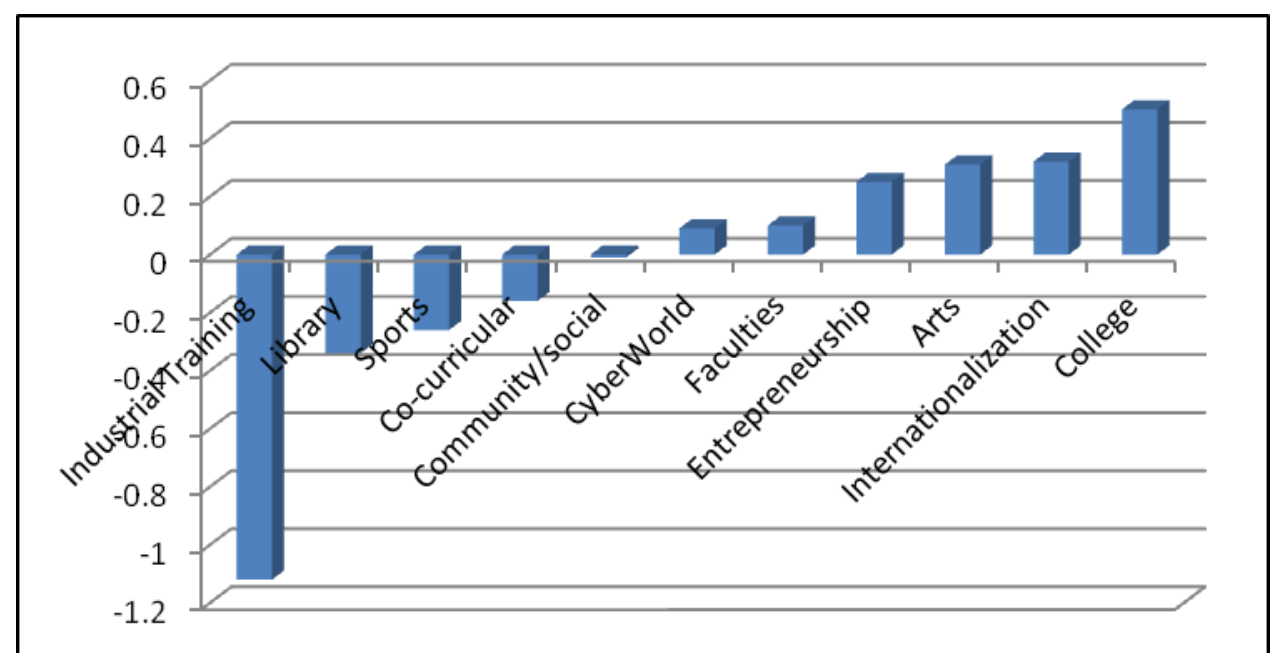

Figure 4. Mean of each sub-construct of Infrastructure

\subsection{Students' Profiling}

Among the 100 students participated in this study, they are from several departments, mainly Department of Electrical, Electronic \& System Engineering (JKEES), Department of Chemical \& Process (JKKP), Department of Civil \& Structural Engineering (JKAS). By segregating their ability measures according to their respective departments, mean value of their ability measures are calculated to determine their infrastructure impact towards their learning experience.

\subsubsection{Department of Chemical \& Process (JKKP)}

Students from JKKP have mean value of +0.93 logit with maximum logit is at +3.89 and minimum logit at -0.49 . The gap between the highest location; the students who has most learning experience impact on the infrastructure, and the lowest location; the students with least learning experience impact is 4.38 logit apart. This information indicates that most of the students agreed that the infrastructure domain made an impact towards their learning experience. Figure 5 shows a snapshot of the Wright map for all the students in department JKKP, a total of 40 students against 69 items. Due to limited space, some of the items were truncated from the snapshot. Figure 5 revealed that $45 \%$ of the JKKP students agreed that Infrastructure domain made a significant contribution towards their learning experience. Another $50 \%$ agrees only $48 \%$ of all the items under Infrastructure domain made an impact on their learning experience. The rest of them agreed that some of the items made an impact while the rest did not made an impact at all towards their learning experience.

\subsubsection{Department of Civil \& Structural Engineering (JKAS)}

Second highest mean value is students from JKAS with mean value of +0.80 logit. The maximum value is at +3.89 logit and the minimum value is at -0.36 logit, yielding a gap value of 4.25 logit apart. There are 27 students altogether in JKAS and $38 \%$ of the students located above the highest most item at +0.96 logit, indicating that these group of students agreed that the infrastructure domain influenced their learning experience. Another $52 \%$ finds that only $49 \%$ of all the items under infrastructure domain influenced their learning experience while the rest $15 \%$ of JKAS students only agreed to $22 \%$ of the items under infrastructure domain. Reference to the location of those JKAS's student is in the snapshot of the Wright map in Figure 6.

\subsubsection{Department of Electrical, Electronic \& System Engineering (JKEES)}

The third highest mean value comes from students in JKEES department with mean at +0.65 logit. The most agreeable JKEES's student is located at the maximum logit at +1.77 and the least agreeable student is located at the minimum location at -0.29 logit on the snapshot of the Wright map in Figure 7. 21\% from the total 33 students from JKEES agrees that all the items under infrastructure domain made a significant impact towards their learning experience. This group of students are located even above the maximum item with logit measure of +0.96 . Another $70 \%$ of them agree that $49 \%$ out of total 69 items influenced their learning experience and $9 \%$ of the students agree to only $25 \%$ of all the items. 


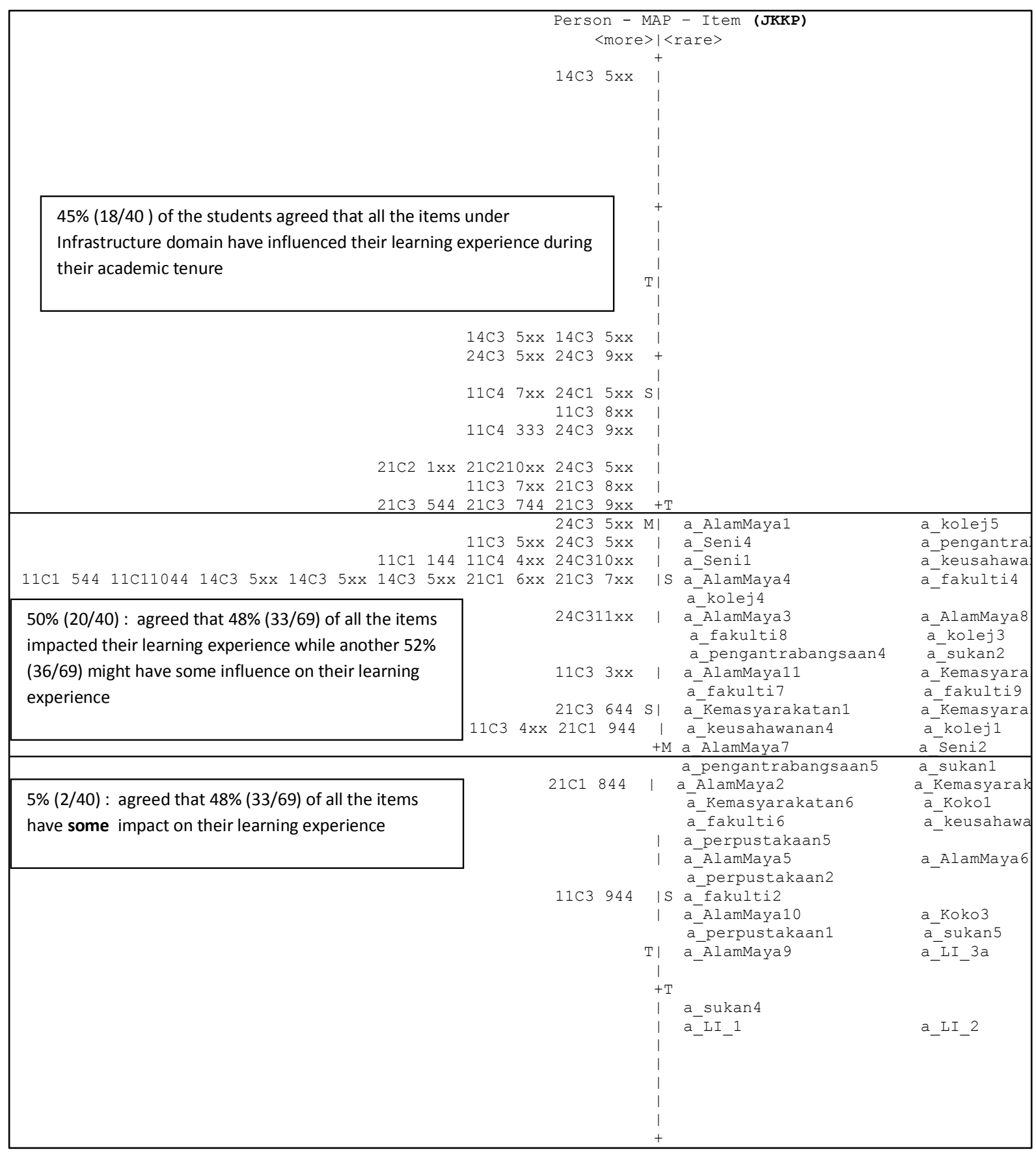

Figure 5. Snapshot of JKKP Students on Wright Map 


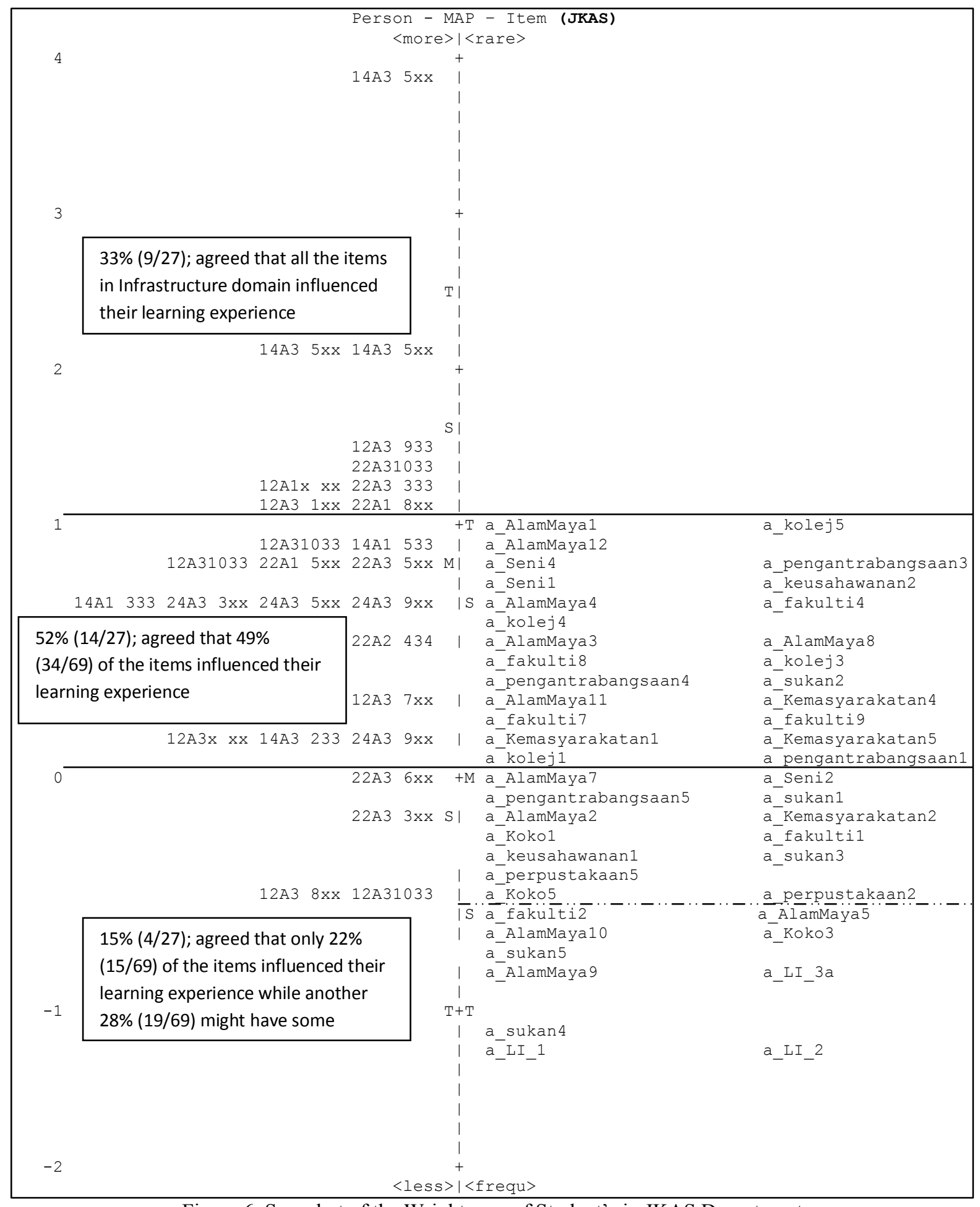

Figure 6. Snapshot of the Wright map of Student's in JKAS Department 


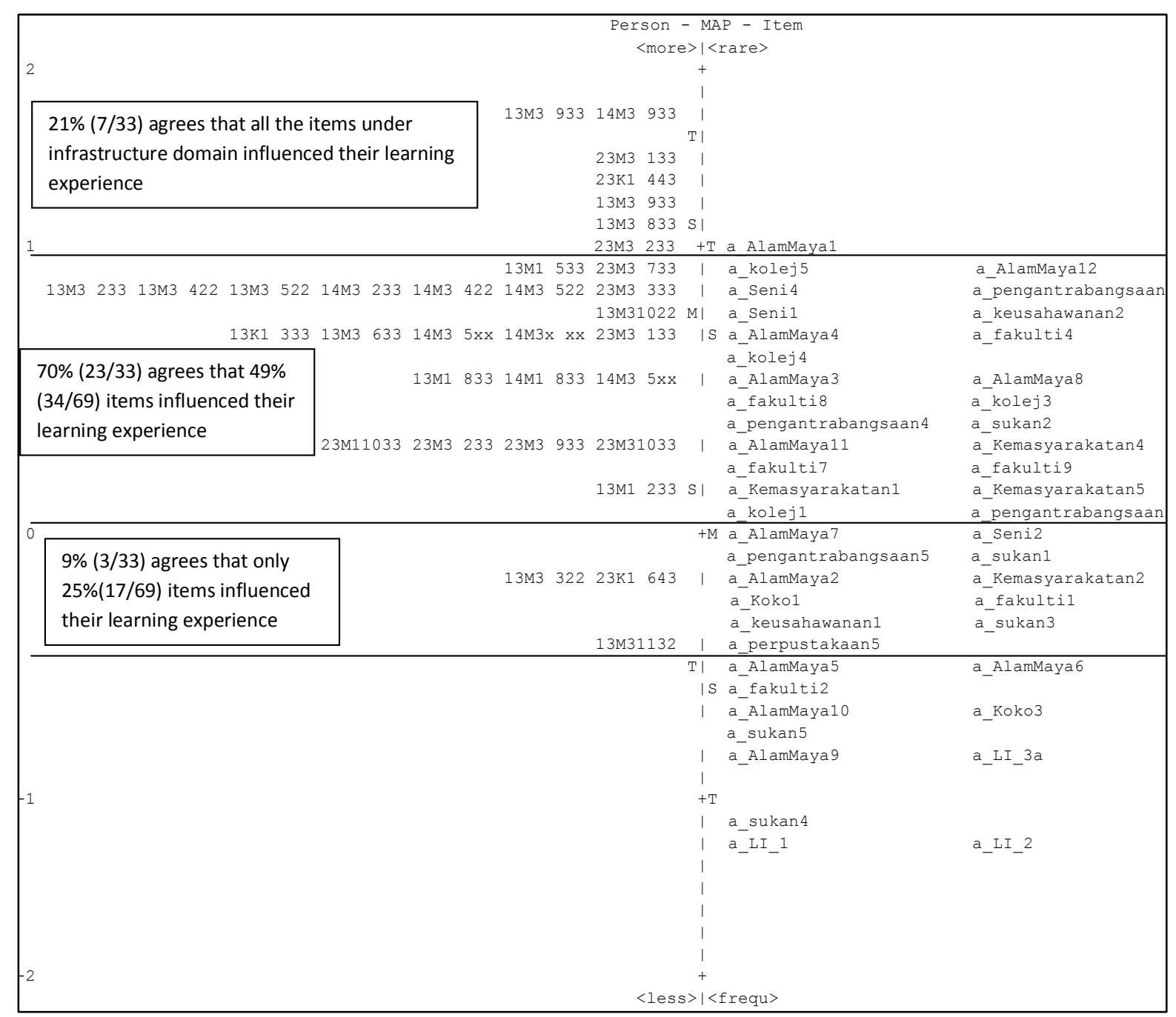

Figure 7. Snapshot of the Wright map of Student's in JKEES Department

\section{Conclusion}

Learning experience is a process by itself where students are being affected by their surroundings and these experiences are well embedded in their subconscious mind (Kolb, 1984). UKM has made an effort towards enhancing and improving the total learning experience of their students. Assessment and evaluation of their students' total learning experience is done continuously to provide the students perception on the facilities provided to them. UKM has made a standard assessment on the total learning experience (Sung et al., 2006; Symon, 2008; Azrilah et al., 2012) This paper describes only on the learning experience pertaining to the infrastructure provided by UKM on its students particularly to the engineering students.

The findings showed that these group of engineering students indicated that the infrastructure provided to them has made an impact in their learning experience with a mean value of +0.80 logit. The students whom perceive that they have a significant impact on infrastructure are located at +3.89 logit and the least influence located at -0.49 logit, with a gap of 4.4 logit. The least influenced item is the item located at the highest most location on the measurement ruler that is item a_AlamMaya1 with +0.96 logit. The item seeks the students' satisfaction on the computer and broadband facilities provided by the university, which in this case they perceived as non-satisfactory item. The most influential item is item a_LI3b, located at -1.26 logit, which seeks students perception on the industrial training provided to them. This item seeks the students perception before they undergone the industrial training process, and it is interesting to note that the students perceived that they has not increase their skills after the industrial training process. 
Among the 11 sub-constructs within infrastructure, the students perceived that the most influential item is the industrial training process and the least influential item is the college facilities. This gives an indication that UKM has to investigate further on why the colleges facilities has less impact on the students learning experience.

$45 \%$ of JKKP students agree that all the infrastructure domain made a significant impact on their learning experience, compared to $33 \%$ from JKAS and $21 \%$ of JKEES students.

\section{Acknowledgements}

The authors would like to thank Universiti Kebangsaan Malaysia for providing the research grant (PTS-2011-018 and UKM-OUP-NBT-28-131/2011).

\section{References}

Andrich, D. (1988). Rasch Models for Measurement (Quantitative Applications in the Social Sciences). California: Sage.

Azrilah Abdul Aziz, Nuraini Khatimin, Khairul Anwar Mastor, \& Azami Zaharim. (2012). Total Learning Experience (TLE) of Engineering Students in Malaysia: Case Study of UKM. Proceeding of International conference on Statistics in Science, Business and Engineering 2012 (ICSSBE2012), September 10-12, 2012, Langkawi, Malaysia.

Chalabine, M. (2008). what a deep learner does that a surface does not. Retrieved November 22, 2012, from http://www.ida.liu.se/ mikch/resource/publ/ChalabineDeepApproach.pdf

Dasar Pengalaman Pembelajaran Menyeluruh Universiti Kebangsaan Malaysia (DPM UKM) (The Foundation for Learning Experience in Universiti Kebangsaan Malaysia). (2009). Universiti Kebangsaan Malaysia's official portal, Academic Development Centre: UKM Bangi, 25 Mac, 2013. Retrieved from http://www.ukm.my/fpi/Info\%20KUALITI/Dasar/Dasar\%20Pengalaman\%20Menyeluruh.pdf

Dewey, J. (1938). How we Think. Buffalo, NY: Prometheus Book.

Dewey, J. (1944). Democracy and education. New Yorl: Free Press.

Fisher, W. P. Jr. (2007). Rating Scale Instrument Quality Criteria. Rasch Measurement Transactions, 21(1), 1095.

Keefe, J. W. (1979). Learning style: An overview. NASSP's Student learning styles: Diagnosing and proscribing programs . Reston, VA. National Association of Secondary School Principles.

Kolb, D. A. (1984). Experiential learning: Experience as the source of learning and development. Englewood Cliffs, New Jersey: Prentice Hall. Retrieved from http://www.learningfromexperience.com/images/uploads/process_of_experiential_learning.pdf

Linacre, J. M. (1994). Sample size and item calibration stability. Rasch Measurement Transaction, 7(4), 328.

Linacre, J. M. (2004). Rasch Model Estimation: Further Topics. Journal of Applied Measurement, 5(1), 95-110. Retrieved March 25, 2013, from http://www.winsteps.com/a/Linacre-estimation-further-topics.pdf

Lunz, M. E. (2012). Using the very useful Wright map. Retrieved November 22, 2012, from http://www.rasch.org/mra/mra-01-10.htm

McLeod, S. A. (2010). Kolb's learning styles and experiential learning cycle. Retrieved November 22, 2012, from http://www.simplypsychology.org/learning-kolb.html

Prosser, M. (2008). The Scholarship of Teaching and Learning: What is it? A Personal View. International Journal for the Scholarship of Teaching and Learning, 2(2), 1-4.

Rasch G. (1960). Probabilistic models for some intelligence and attainment tests. University of Chicago Press, Chicago.

Stewart, K. L., \& Felicetti, L. A. (1992). Learning styles of marketing majors. Educational Research Quarterly, 15(2), 15-23.

Sung, J., Raddon, A., \& Ashton, D. (2006). Skills Abroad: A Comparative Assessment of International Policy Approaches to Skills Leading to the Development of Policy Recommendations for the UK, Skills for Business Research Report 16, Wath-on-Dearne: Sector Skills Development Agency (Evidence to the Leitch Review) 135 pages. 
Symons, R. (2008). Analysing, evaluating and reporting on the student experience at the University of Sydney: responding to the changing demands of stakeholders. Society for Research into Higher Education Conference, Liverpool, UK. 3-5 December.

Wilson, M. (2011). Some notes on the terms: Wright map. Rasch Measurement Transactions, 25(3), 1331.

Wright, B. D. (1992). Measurement for Social Science and Education A History of Social Sciences Measurement. Retrieved March 25, 2013, from http://www.rasch.org/memo62.htm

Wright, B. D., \& Mok, M. C. (2004). An Overview of the Family of Rasch Measurement Models. A chapter in the Introduction of Rasch Measurement. Chapter 1. Pg 1-24. Retrieved March 15, 2013, from http://www.jampress.org/irmch1.pdf 